\title{
Wisdom teeth - A major problem in young generation, study on the basis of types and associated complications
}

\author{
G. Biswari ${ }^{1}$, P. Gupta ${ }^{2}$, D. Das ${ }^{1}$ \\ ${ }^{1}$ Lecturer, ${ }^{2}$ Medical Officer, Department of Dental Surgery, College of Medical Sciences, Bharatpur, Chitwan, Nepal
}

\begin{abstract}
The aim of this study was to describe the characteristics and types of the impacted mandibular third molar at the highest risk for pain and pericoronitis using clinical and radiographic analysis. A total of 239 volunteers, including 147 (61.5\%) male and 92 (38.5\%) female patients presenting with acute pericoronitis, participated in the study. The mean age of the participants was 28 years (range 16-40 years). The analysis of type, angulations and eruption level of the mandibular third molar were achieved by using I.O.P.A. X-ray and in few cases, lateral oblique of mandible. While mesioangular impaction was the most frequent angulation (44.4\%), horizontal impaction was quite less (11\%). Vertical impaction (27.6\%) was slightly higher than distoangular impaction (15.9\%) and aberrant $(0.8 \%)$.
\end{abstract}

Key words: Impacted third molar, pericoronitis, types of impaction

\section{Introduction}

Impaction occurs where there is prevention of complete eruption into a normal functional position of one tooth by another, due to lack of space (in the dental arch), obstruction by another tooth or development in an abnormal position. ${ }^{1,2}$ An impacted tooth may be:

Completely impacted: when entirely covered by soft tissue and partially or completely covered by bone within the bony alveolus.

Partially erupted: when it has failed to erupt into a normal functional position

\section{Review of the literature}

'Our ancestors had larger jaws so there was room in the human mouth for 32 permanent teeth, including third molars-wisdom teeth. But now our jaws are Correspondences: Dr. G. Biswari

E-mail:dr_arian3@rediffmail.com smaller. The result: There's no longer room in most of our mouths to house 32 teeth. So the last teeth we develop — our wisdom teeth,often become impacted or blocked from erupting.' ${ }^{3}$

A major conclusion of evolution is that the human jaw has shrunk from its much larger ape size to the smaller modern human size as humans evolved. In short, evolution has produced 'an increase in brain size at the expense of jaw size. ${ }^{4}$ In the process, the jaw has became too small for the last teeth to erupt which are normally the third molars.

Research now indicates that the reasons for most third molar problems today are not the evolutionary changes but something else. These reasons include a change from a coarse abrasive diet to a soft western diet, lack of proper dental care, and genetic factors, possibly including mutations. 
G. Biswari et al ,Wisdom teeth - A major problem in young generation,

The "wisdom teeth" or last molars, are in man, approaching a vestigial condition since they generally do not appear until relatively late, between the ages of twenty and thirty years, and in many persons are never cut at all. In a large percentage of individuals, they are useless, and they often become impacted and have to be removed surgically. ${ }^{5}$

The loss of an organ in evolution purely as a result of disuse, also called Lamarckian Evolution, has now been thoroughly disproved. The belief that wisdom teeth are vestigial organs that lack a function in the body (as was previously believed for the appendix), is less common today but still evident. It is also commonly assumed by the general public.

Another problem cited for their removal is the possibility of cysts and tumors developing in the sac surrounding an impacted wisdom tooth. This abnormality is relatively rare-usually around one percent of all impacted third molars are surrounded by cysts, although one study found the rate was $11 \% .6,7$

One reason they were believed to cause problems was that the wisdom teeth normally erupt last, between 18 and 25 years of age. Consequently it was assumed that if not enough room did not exist in the jaw, teeth crowding would result. Since they erupt at about the time when the youth goes off into the world to become 'wise' the name 'wisdom teeth' was used to describe them. ${ }^{8}$ In $13-15 \%$ of patients they never develop and only from 9 to $24 \%$ of all cases become impacted, usually because they are pointed in the wrong direction when they break through the gum, causing them to push against the second molar. ${ }^{9}$

Although third molars have the greatest incidence of impaction of all teeth, the impaction risk is much smaller than the proponents of prophylactic odontectomy (the routine removal of asymptomatic unerupted teeth) claim. ${ }^{10}$

\section{Materials and methods}

This study was conducted at the Dental Dept. of the College of Medical Sciences \& Teaching Hospital, Bharatpur, Nepal. Total Two hundred thirty nine patients were selected for this study with complain of pain and swelling over back teeth of the lower jaw.

Intra oral Periapical Radiographs and when necessary, lateral oblique radiographs of the mandible of patients with impacted third molar were taken.

Differentiation of the type was done on the basis of depth and angulation of impacted teeth with occlusal plan. Depth of impaction was measured in millimetres with a pair of callipers and ruler. For the measurement, a perpendicular from the alveolar margin to the amelocemental junction of the impacted teeth was measured with the callipers and read from the ruler.

All extractions were done under local anaesthesia, the bur technique with preservation of the lingual plate was used, while in 23 cases bur or lingual bone split technique was used. Personal details including age, sex, diagnosis, X-ray type, type of impaction, associated pathology, antibiotics used were recorded. Forty-four percent of the patients were in the age of 16-25 years.

\section{Results}

There were 239 patients consisting of 147 males and 92 females. Two hundred and thirty-nine impacted mandibular third molar teeth were extracted. Details of the age of patients and the types of impaction are presented on Table 1. One hundred forty-four (60.3 $\%$ ) extractions were from patients aged 25 years and below while, ninety-five $(39,7 \%)$ were extracted from elder patients. Mesioangular impaction was the most 
frequent angulation $(44.4 \%)$ which was easy to extract compared to horizontal impaction which was quite less (11\%) but most difficult to extract. Vertical impaction
(27.6\%) was slightly higher than distoangular impaction $(15.9 \%)$ and aberrant $(0.8 \%)$.

\section{Table-1: Age distribution and type of impaction}

\begin{tabular}{lcccc}
\hline Types & $\mathbf{1 6 - 2 5} \mathbf{y r}$ & $\mathbf{2 6 - 3 5} \mathbf{~ y r}$ & $\mathbf{3 5} \mathbf{~ y r}>$ & Total (\%) \\
Mesio-angular & 63 & 36 & 07 & $106(44.4 \%)$ \\
Vertical & 40 & 23 & 03 & $66(27.6 \%)$ \\
Disto-angular & 22 & 15 & 01 & $38(15.9 \%)$ \\
Horizontal & 18 & 08 & 01 & $27(11.3 \%)$ \\
Aberrant & 01 & 00 & 02 & $02(00.8 \%)$ \\
\hline Total & 144 & 82 & 13 & $239(100 \%)$ \\
$(\%)$ & $60.3 \%$ & $34.3 \%$ & $5.4 \%$ & \\
\hline
\end{tabular}

\section{Types of impaction}

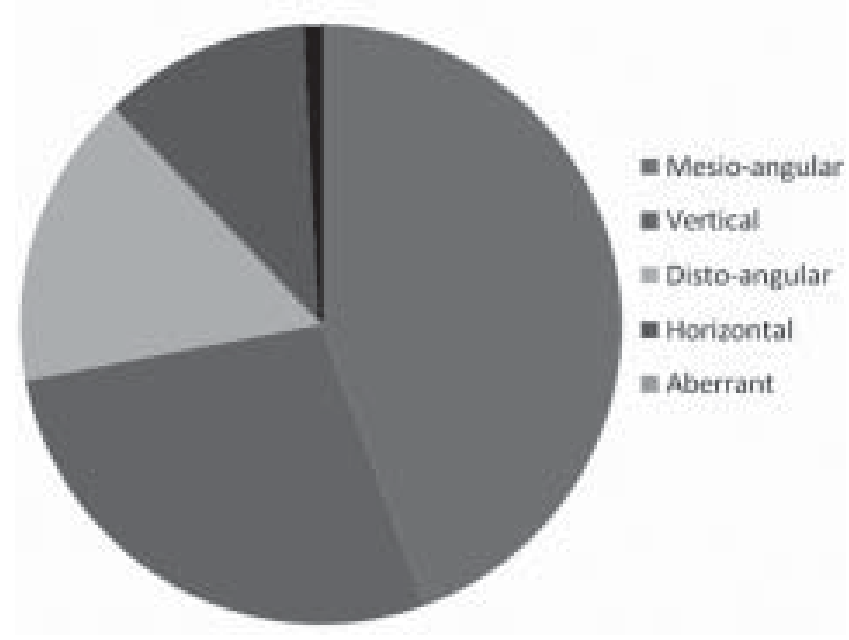

involved is associated with less expected costs and disability than prophylactic removal of wisdom teeth. ${ }^{10}$

Although a competent surgeon can reduce serious problems later in life by appropriate removal of third molars, routine prophylactic removal is now regarded by many researchers as ill advised. ${ }^{9}$ A review of 12 studies on prophylactic removal found 'there is little justification for the removal of pathology free impacted third molars. ${ }^{12}$ According to Samsudin and Mason ${ }^{13}$, pain was once the major reason asymptomatic wisdom teeth were removed (73.7\% of all cases). Surgeons

\section{Discussion}

For generations, many dentists recommended extraction of impacted wisdom teeth because the procedure in the young was 'much easier than in later years, when the bone became more dense. Also, the younger the patient, the better the procedure will be tolerated. ${ }^{11}$ This advice has now been replaced with the conclusion that "extracting only those third molars that remain impacted and become pathologically usually set a removal decision threshold based on several criteria and if a tooth has characteristics which exceed the threshold, it is removed ${ }^{14}$. This requires training, experience and knowledge.

Teeth extraction can cause postoperative pain, swelling, and tempromandibular joint dysfunction. ${ }^{15}$ The most common complications include infection and dry socket, trauma to the neurovascular bundle and 
G. Biswari et al,Wisdom teeth - A major problem in young generation,

temporary or permanent paresthesia or anesthesia of the lip, trauma to the lingual nerve, tongue numbness (temporary or permanent), root segments left in the socket and risk of damage to adjacent teeth. ${ }^{16}$ One Michigan study found that about ten percent of all such operations resulted in complications, mostly minor, but included some serious problems such as infection, persistent bleeding, severe tooth socket inflammation, permanent numbness of the lip and tongue and occasionally, catastrophic haemorrhage which could be lethal. ${ }^{17,18}$

The impacted mandibular third molar tooth is common among adults. It has been estimated that 1 out of every 11 mandibular third molar teeth, aged 15 to 35 years was impacted. In older adults, 1 in every 46 mandibular third molar teeth was reported to be impacted. This study agrees with the trend that impacted third molar teeth are common in young adults and it is important to know type of impaction before planning of management.

\section{Conclusion}

Several factors have been found to be important in causing third molar problems and malocclusion. The most important factor is probably diet, but the influence of other factors including mutations, need to be examined more fully to understand why wisdom teeth are more often a problem today.

Impaction of mandibular $3^{\text {rd }}$ molar is a common problem in adult and it causes pain, pericoronitis and some times more serious problems like cellulitis, submandibular space infections in delayed condition, that is why the conclusion of this study is better to extract impacted $3^{\text {rd }}$ molar in initial stage after confirming the type and eruption pattern of particular teeth by radiograph to avoid delayed problem associated with impaction like post operative pain and infection.

\section{References}

1. British Standards Institution. British standard glossary of dental terms. London: BSI, 1983.

2. J.T. Welch, R.W. Graves. Diagnosis, localisation and pre-operative consultation for the difficult impaction. Dent Clin North Am 1979; 16:347-59

3. Ebbert, S. and Sangiorgio, M. Facing the dreaded third molar. Prevention 1991, 43(7):108-10.

4. A.J. MacGregor, The Impacted Lower Wisdom Tooth, Oxford University Press, NewYork, 1985, 5.

5. J.S. Rogers, T. Hubbell, C. Byers, Man and the Biological World, McGraw-Hill, New York 1942, 313.

6. S.F. Dachi, and F.V. Howell, Survey of 3874 routine fullmouth radiographs: a study of impacted teeth. Oral Surgery, Oral Medicine, Oral Pathology 1961, 14:1165-9.

7. F.Moursheed. A rentgenographic study of dentigerous cysts: incidence in a population sample. Oral Surgery, Oral Medicine and Oral Pathology, 1964, 18:47-53

8. A.J. MacGregor, The Impacted Lower Wisdom Tooth, Oxford University Press, New York, 1985, 3.

9. R.J. Robinson, N.S.Vasir, The great debate: do mandibular third molars affect incisor crowding? A review of the literature. Dental Update, 1993, 20 (6) : 242-6.

10. H Singh, K. Lee, A.F. Ayoub, Management of asymptomatic impacted wisdom teeth: a multicentre 
Journal of College of Medical Sciences-Nepal,2010,Vol-6,No-3

comparison. British Journal of Oral and Maxillofacial

Surgery, 1996,34:389-93

11. N. Wood, The Complete Book of Dental Care, Hart Publishing Company, New York, 1978.

12. F. Song, et al. Prophylactic removal of impacted third molars: an assessment of published reviews. British Dental Journal, 1997, 182(9):339-46.

13. A.R Samsudin, A.D. Mason, Symptoms from impacted wisdom teeth. British Journal of Oral and Maxillofacial Surgery, 1994, 32(6):380-3.

14. M.R. Brickley, I. M. Prytherch, E.J. Kay, J.P. Shepherd, A new method of assessment of clinical teaching: ROC analysis. Medical Education, 1995, 29:150-3.
15. P. Capuzzi, L. Montebugnoli, M. Vaccaro, Extraction of third molars. Oral Surgery, Oral Medicine, Oral Pathology, 1994, 77(4):341-3.

16. M.S. Leonard, Removing third molars: a review for the general practitioner. Journal of the American Dental Association, 1992, 123(2):77-82.

17. M. Leff, Hold on to your wisdom teeth. Consumer Reports on Health, 1993, 5(8):4-85.

18. D.A.S. Marshall, C. Berry, A. Brewer, Fatal disseminated intravascular coagulation complicating dental extraction. British Journal of Oral and Maxillofacial Surgery, 1993,31:178-9. 